\title{
Timoma e tumor de células da granulosa em gata
}

\author{
Thymoma and granulosa cell tumor in cat \\ Heloisa Justen Moreira de Souza', Fernanda Vieira Amorim², Ellen Jafféz, Katia Barão \\ Gorgozinho ${ }^{3}$, Raquel Souza Calixto ${ }^{3}$, Jaqueline Gomes da Silva ${ }^{3}$ \& Evandro de Toledo-Piza ${ }^{4}$
}

\begin{abstract}
RESUMO
O timoma é uma neoplasia incomum em gatos domésticos que se localiza no mediastino anterior. Tumores de células da granulosa são extremamente raros em gatas e origina-se do estroma gonadal do ovário, que pode ser resultante do cordão sexual da superfície do epitélio celomático ou dos tubos mesonéfricos. Uma gata, sem raça definida, esterilizada, com dez anos de idade foi encaminhada para Clínica Veterinária particular (Gatos \& Gatos Vet), Rio de Janeiro. apresentando dispnéia e efusão pleural. Foram drenados trezentos mililitros de fluido hemorrágico através da toracocentese. As avaliações radiográficas do tórax demonstraram uma massa no mediastino anterior. A biopsia incisional foi realizada através da toracotomia. O lobo pulmonar cranial esquerdo se encontrava envolto pelo tecido tumoral. A avaliação histopatológica revelou timoma epitelial de células claras com epitélio primordial associado. Foi realizado o tratamento quimioterápico utilizando o protocolo COP durante seis semanas, o qual foi curativo. Transcorridos vinte e quatro meses, a gata apresentou cios constantes, além de uma massa abdominal. Realizou-se uma biopsia excisional através da laparotomia exploratória sendo identificado um tumor de células da granulosa através de análise histopatológica. Após um ano e meio da ressecção deste tumor, a gata se apresenta em ótimo estado geral. Não foi observada nenhuma correlação entre o timoma e o tumor de células da granulosa na gata. No timoma, classificado na categoria II, tem-se como opção terapêutica à quimioterapia como tratamento único, empregando-se a ciclofosfamida, a vincristina e a prednisona. A existência do tumor de célula da granulosa deve ser considerada no diagnóstico diferencial de distúrbios comportamentais em gata, mesmo naquelas, que foram submetidas à esterilização.
\end{abstract}

Descritores: timoma, tumor de células da granulosa, gato.

\section{ABSTRACT}

Thymoma is an unusual tumor in cats located in the anterior mediastinum. Granulosa cell tumors are extremely rare in the cat. They are gonadal stromal tumors and may arise from the sex cords of the surface celomic epithelium or the mesonephric tubules. A ten year-old neutered female domestic shorthair cat was referred to a private Veterinary Cat Clinic (Gatos \& Gatos Vet), Rio de Janeiro, Brazil, because of dyspnea and pleural effusion. A toracocentesis was performed and $300 \mathrm{~mL}$ of pleural fluid was removed. Radiography revealed a smooth, well-delineated mass in the mediastinum that compressed the cranial lung lobes. A toracotomy was performed to take an incisional biopsy. The tumoral tissue was involving the lung cranial left lobe. Histopathological sections taken from the excised mass consisted of well-differentiated lymphoid cells with dark nuclei and little cytoplasm and some clusters of epithelial cells. These findings were consistent with well-differentiated thymoma. Chemotherapy with COP protocol was curative in six weeks. A granulosa cell tumor was diagnosed two years after the treatment of thymoma, when the cat was presented with persistent estrus and an abdominal mass. There were no futher problems reported for this case at one and a half year post the later laparotomy. There was no correlation between the two different tumors developed in this cat. Type II thymomas can be treated only by chemotherapy using cyclophosphamide, vincristine and prednisone. Granulosa cell tumors should be included in the differential diagnosis in cats that are presenting behavior changes, even in neutered ones.

Key words: thymoma, granulosa cell tumor, cat. 


\section{INTRODUÇÃO}

O timoma é uma neoplasia que se localiza no mediastino anterior, usualmente benigno e a ocorrência de metástases é rara [6,11,15-17,19,23]. A média de idade dos gatos afetados varia entre nove e dez anos de idade [17].

O sintoma mais consistente é a dispnéia inspiratória pela compressão da massa nas estruturas adjacentes e quando há efusão pleural $[8,23]$. Vômito, regurgitação ou disfagia podem ser observados pela compressão esofageana $[5,8,11,17,23]$.

Na presença de miastenia gravis, os gatos apresentam fraqueza muscular, megaesôfago, polimiosite e miocardite $[5,8,11,30]$. A dermatite esfoliativa também é observada com frequiência [8,24].

Os achados radiográficos do tórax revelam radiopacidade no mediastino anterior, o coração pode estar desviado lateralmente e pode haver efusão pleural $[9,15$, $16,23,29]$. O diagnóstico definitivo requer avaliação citológica ou exame histopatológico [5,17,27].

A excisão cirúrgica da massa é freqüentemente curativa [17]. Outra modalidade de terapia é a sua associação com a quimioterapia [17,27,29].

Tumores de células da granulosa originam-se do estroma gonadal $[19,28]$ e são extremamente raros em gatas devido ao grande número de fêmeas jovens submetidas a ovariossalpingo-histerectomia $[2,13,14]$. A metástase ocorre freqüentemente na cavidade abdominal e nos pulmões $[1,3,28]$.

$\mathrm{O}$ tumor pode causar ciclos estrais irregulares $[18,21,28]$, distensão abdominal, êmese, letargia e anorexia $[1,3,10,28]$.

O tratamento de escolha é a ressecção cirúrgica através da laparotomia exploratória [18].

O objetivo deste trabalho é relatar o caso de uma gata na qual foram evidenciados a presença de duas neoplasias incomuns, timoma e tumor de célula da granulosa, em um período de dois anos.

\section{RELATO DE CASO}

Uma gata, sem raça definida, esterilizada, com dez anos de idade foi encaminhada à Clínica Veterinária Gatos \& Gatos Vet., Rio de Janeiro, apresentando dificuldade respiratória e intolerância ao exercício, notada pelo proprietário há aproximadamente vinte e dois dias. No histórico foi constatado que o exame radiológico da cavidade torácica na posição ventrodorsal ortostática demonstrara a presença de efusão pleural no hemi- tórax esquerdo (Figura 1A). O animal fora submetido a toracocentese e a antibioticoterapia, não havendo resposta terapêutica satisfatória.

Ao exame clínico, a gata adotava uma postura em decúbito esternal, com os membros torácicos em abdução. A freqüência respiratória era de 54 movimentos respiratórios por minuto, com respiração rápida e do tipo abdominal. No hemitórax esquerdo, a auscultação pulmonar evidenciou os sons respiratórios diminuídos e os sons cardíacos abafados. A frequiência cardíaca era de 200 batimentos por minuto e os sons cardíacos eram fortemente audíveis no hemitórax direito. $\mathrm{O}$ animal encontrava-se intolerante à manipulação, magro $(2,5 \mathrm{~kg})$ e com um grau de $7 \%$ de desidratação. As mucosas apresentavam-se normocoradas. A pele apresentava áreas multifocais de alopecia, com escoriações e eritema. O pêlo estava sem brilho e notava-se uma infestação leve por pulgas.

Para a realização da toracocentese no hemitórax esquerdo, o felino recebeu quetamina ${ }^{1}$ e diazepam ${ }^{2}$ nas dosagens de $2,0 \mathrm{mg} / \mathrm{kg}$ e $0,2 \mathrm{mg} / \mathrm{kg}$, respectivamente, por via intravenosa. Aproximadamente $300 \mathrm{mi}-$ lilitros de líquido hemorrágico foram drenados. A análise citológica revelou se tratar de um transudato modificado, apresentando hemácias e leucócitos morfologicamente normais. Após remoção do líquido torácico, as avaliações radiográficas do tórax nas posições lateral e ventrodorsal ortostática demonstraram uma massa no mediastino anterior sugestivo de neoplasia, como também foi observada a presença de fraturas da nona, décima, décima primeira e décima segunda costelas no hemitórax direito (Figura 1B).

O resultado do teste ELISA para detecção do antígeno para o vírus da leucemia felina (FeLV), do anticorpo para o vírus da imunodeficiência felina (FIV) e o teste para detecção de antígeno do parasita Dirofilaria immitis foram negativos. $\mathrm{O}$ exame hematológico e a bioquímica sérica não apresentaram alterações dignas de nota.

O exame ultra-sonográfico da cavidade torácica detectou a presença de uma massa tumoral ovalada de $664,7 \mathrm{~mm}^{2}$, com várias formações císticas, que estava em contato com a parede aórtica, sem provocar derrame pericárdico. Transcorridos cinco dias, a gata encontrava-se novamente dispnéica. A avaliação radiográfica do tórax na posição ventrodorsal ortostática demonstrou efusão pleural no hemitórax esquerdo, com desvio da silhueta cardíaca para o lado direito, sendo então, drenados $100 \mathrm{~mL}$ de líquido serossanguinolento. $\mathrm{O}$ felino 
foi encaminhado para a toracotomia para realização e de biopsia incisional (Figura 2A).

A medicação pré-anestésica utilizada incluiu midazolam $^{3}$, na dosagem de $0,2 \mathrm{mg} / \mathrm{kg}$ e buprenorfina ${ }^{4}$, na dosagem de $0,005 \mathrm{mg} / \mathrm{kg}$, ambos por via intramuscular. A indução anestésica foi realizada com tiopental ${ }^{5}$, na dosagem de $12,5 \mathrm{mg} / \mathrm{Kg}$, por via intravenosa e a manutenção com isoflurano ${ }^{6}$. A via de acesso foi o quinto espaço intercostal esquerdo. Foram observados nódulos de coloração branco-acinzentada aderidos a pleura visceral e parietal. O lobo pulmonar cranial esquerdo estava comprimido por um tecido semifriável, de coloração esbranquiçada, que impedia a expansão do mesmo e a visualização do coração. As amostras teciduais foram removidas e acondicionadas em frascos contendo formalina a $10 \%$. A decorticação foi feita numa área restrita da pleura visceral, porém não foi estendida devido ao extravasamento de ar. A cavidade torácica foi suturada com pontos separados em forma de $\mathrm{x}$, utilizandose o fio polipropileno $\mathrm{n}^{\circ} 2-0$. $\mathrm{O}$ dreno torácico foi inserido no oitavo espaço intercostal, em virtude do eminente pneumotórax causado pela decorticação.

A biopsia de pele foi realizada devido à dermatite crônica apresentada pelo animal (Figura 2B). As avaliações histológicas da massa mediastinal e da pele revelaram timoma epitelial de células claras com epitélio primordial associado e piodermite superficial aguda com características de dermatite miliar felina, respectivamente (Figura 3A).

$\mathrm{O}$ tratamento quimioterápico utilizado para o timoma com crescimento na região pericapsular foi o COP, que constou de vincristina ${ }^{7}$, na dosagem de $0,5 \mathrm{mg} / \mathrm{m}^{2}$, por via intravenosa, uma vez por semana, contando-se sua aplicação como dia 1; ciclofosfami$\mathrm{da}^{8}$, na dosagem de $50 \mathrm{mg} / \mathrm{m}^{2}$, por via oral, uma vez ao dia, durante quatro dias, nos dias $2,3,4$ e 5; e prednisona $^{9}$, na dosagem de $40 \mathrm{mg} / \mathrm{m}^{2}$, por via oral, a cada 24 horas na primeira semana, sendo que a partir da segunda semana, a dosagem de prednisona passou para $20 \mathrm{mg} / \mathrm{m}^{2}$, por via oral, a cada 48 horas. Esse protocolo teve duração de seis semanas, bem como o acompanhamento semanal hematológico e radiográfico. A gata recebeu tratamento com produto pulicida de contato, havendo melhora da piodermite superficial. As radiografias do tórax realizadas semanalmente revelaram uma redução progressiva da massa no mediastino. $\mathrm{Na}$ quarta semana de tratamento constatou-se uma redução de $50 \%$ da neoplasia. No final da quimioterapia, observou-se remissão completa da neoplasia. Após este tratamento, o animal foi acompanhado através de exames hematológicos e radiográficos após três semanas consecutivas e a cada três meses, não sendo observado a ocorrência de recidiva do tumor.

Transcorridos dois anos do término do tratamento quimioterápico, a avaliação do tórax não demonstrou presença de massa mediastinal ou efusão pleural (Figura 1C). Na palpação abdominal foi observada uma massa localizada próxima ao rim direito. A proprietária relatou que a gata estava apresentando repetições de estros, mesmo após seis anos da esterilização. A ultra-sonografia abdominal detectou a presença de uma massa localizada entre os dois rins, medindo cerca de 10,0 X 5,0 cm. O animal foi submetido a uma laparotomia exploratória (Figura 3B). Na posição anatômica do ovário direito, uma tumoração foi evidenciada com superfície irregular do tipo cerebróide, consistência sólida e formações císticas contendo líquido acastanhado; medindo $10,2 \mathrm{~cm}$ de comprimento, $4,0 \mathrm{~cm}$ de largura, $3,0 \mathrm{~cm}$ de altura e pesando 55 gramas. Não foi observado qualquer sinal de metástase em outros órgãos abdominal. A avaliação histopatológica da neoplasia identificou se tratar de um tumor de células da granulosa (Figura 3C). Após um ano e meio da ressecção cirúrgica do tumor, a gata se apresenta em ótimo estado geral.

\section{DISCUSSÃO}

A ocorrência do timoma é maior em gatos com idade superior a nove anos, não sendo relatada a infecção concomitante pelo vírus da leucemia felina, tal qual o caso descrito [5,17,24]. Este fato é importante no diagnóstico diferencial entre timoma e linfoma mediastinal felino. O exame citológico do timoma demonstra o predomínio de linfócitos maduros, células epiteliais e mastócitos [17]. De acordo com a predominância celular, ele pode ser classificado em linfocítico ou epitelial [4,7, 20]. O linfoma acomete principalmente gatos jovens, com média de dois anos de idade e positivos para o vírus da leucemia felina $[7,16,30]$. Entretanto, o diagnóstico diferencial com linfoma mediastinal linfocítico bem diferenciado, composto por uma população homogênea de linfócitos maduros, que acomete o gato idoso e negativo para o teste do vírus da leucemia felina, só é possível através de biopsia [26].

De um modo geral, os sinais clínicos de gatos com timoma estão relacionados com a expansão da massa tumoral, bem como, da presença de efusão pleural e de síndromes paraneoplásicas, podendo surgir isolada- 

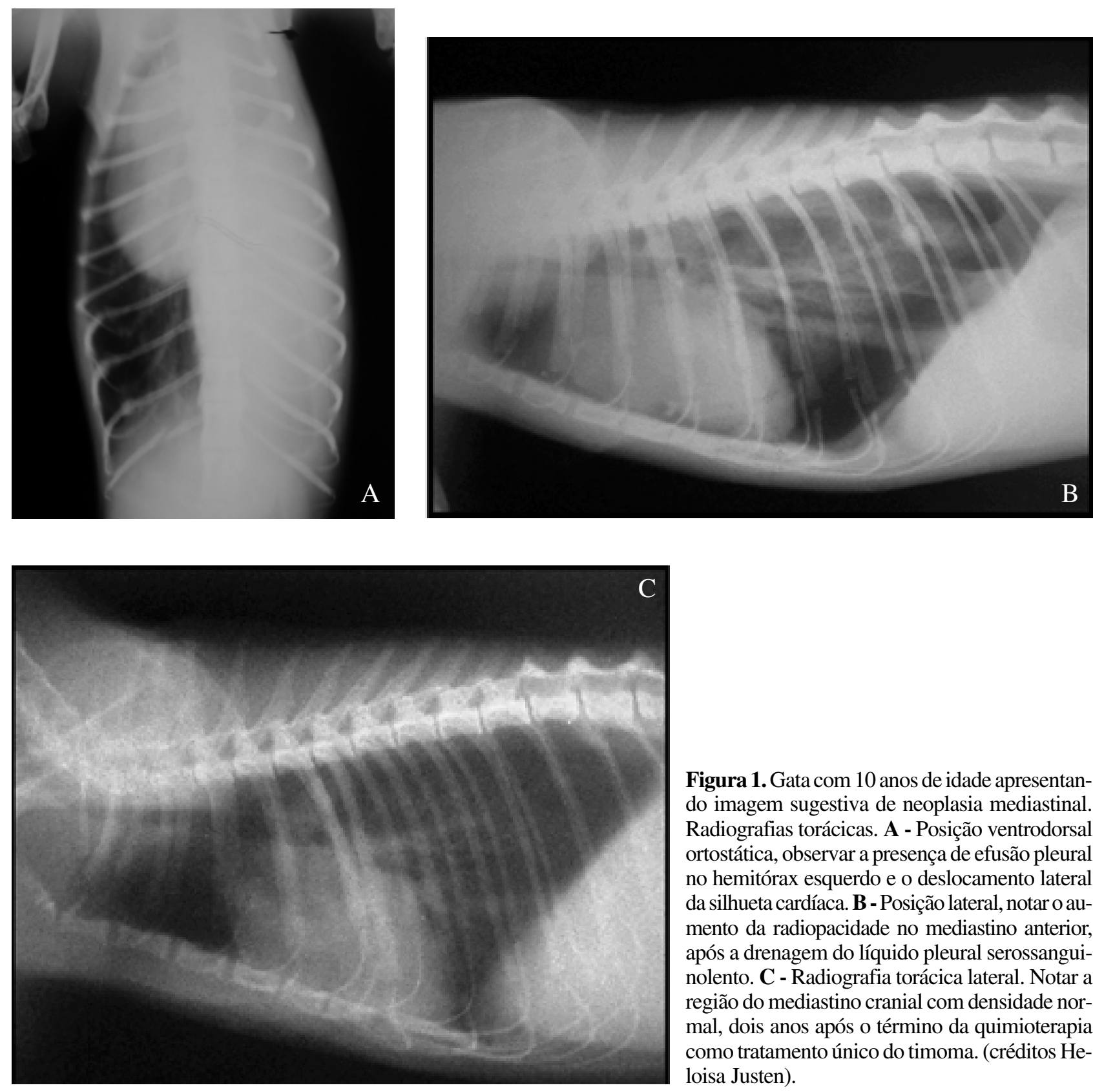

Figura 1. Gata com 10 anos de idade apresentando imagem sugestiva de neoplasia mediastinal. Radiografias torácicas. A - Posição ventrodorsal ortostática, observar a presença de efusão pleural no hemitórax esquerdo e o deslocamento lateral da silhueta cardíaca. B - Posição lateral, notar o aumento da radiopacidade no mediastino anterior, após a drenagem do líquido pleural serossanguinolento. C - Radiografia torácica lateral. Notar a região do mediastino cranial com densidade normal, dois anos após o término da quimioterapia como tratamento único do timoma. (créditos Heloisa Justen).

mente ou concomitantemente $[8,11,30]$. Neste caso, a dispnéia foi o sinal clínico de maior importância, que estava presente em decorrência da quantidade de líquido pleural no hemitórax esquerdo [29]. A efusão pleural está freqüentemente associada à invasão do tumor nos tecidos adjacentes, a semelhança do presente relato [4, $11,29,30]$. A relação entre o timoma e as dermatoses raras tem sido descrita em gatos $[8,22,24]$. Tal ligação não foi observada neste caso, como também nenhum outro sinal de síndrome paraneoplásica e, atribuiu-se a presença da dermatite miliar nesta gata à infestação leve por pulgas. Não foi possível estabelecer a distinção entre timoma e linfoma apenas pelos achados radiológicos [17].
O diagnóstico do timoma é raramente feito a partir do exame citológico da efusão pleural, a exemplo deste relato, onde a análise não foi conclusiva, sendo necessário à realização da biopsia incisional [7,17,29]. O diagnóstico diferencial é fundamental diante da evidência de uma massa mediastinal, visto que o tratamento de eleição para o linfoma é essencialmente quimioterápico, com prognóstico influenciado pela ocorrência concomitante da infecção pelo vírus da leucemia felina $[12,17]$. Em contrapartida, o tratamento de timoma é principalmente cirúrgico, quando este é encapsulado [5,8, 11,16]. No caso descrito, o tumor se estendeu através da cápsula tímica, levando a aderências na pleura visceral 

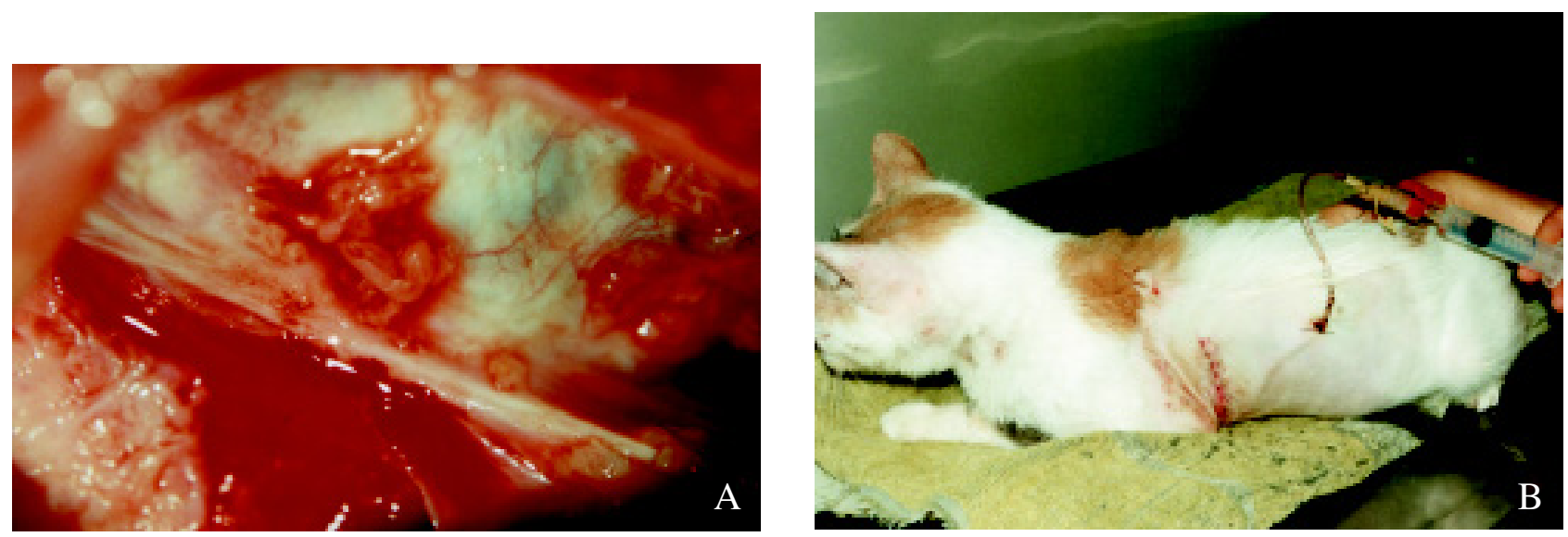

Figura 2. Toracotomia exploratória e complicação do pós-operatório. A - Observar a massa no mediastino anterior com nódulos de coloração branco-acinzentada aderidos à pleura visceral do lobo pulmonar. B - Nas primeiras vinte e quatro horas do pós-operatório, a drenagem de ar foi efetiva para a resolução do pneumotórax, devido à decorticação, através da permanência do dreno torácico no hemitórax esquerdo acoplado a uma válvula de três vias e uma seringa. (créditos Heloisa Justen).
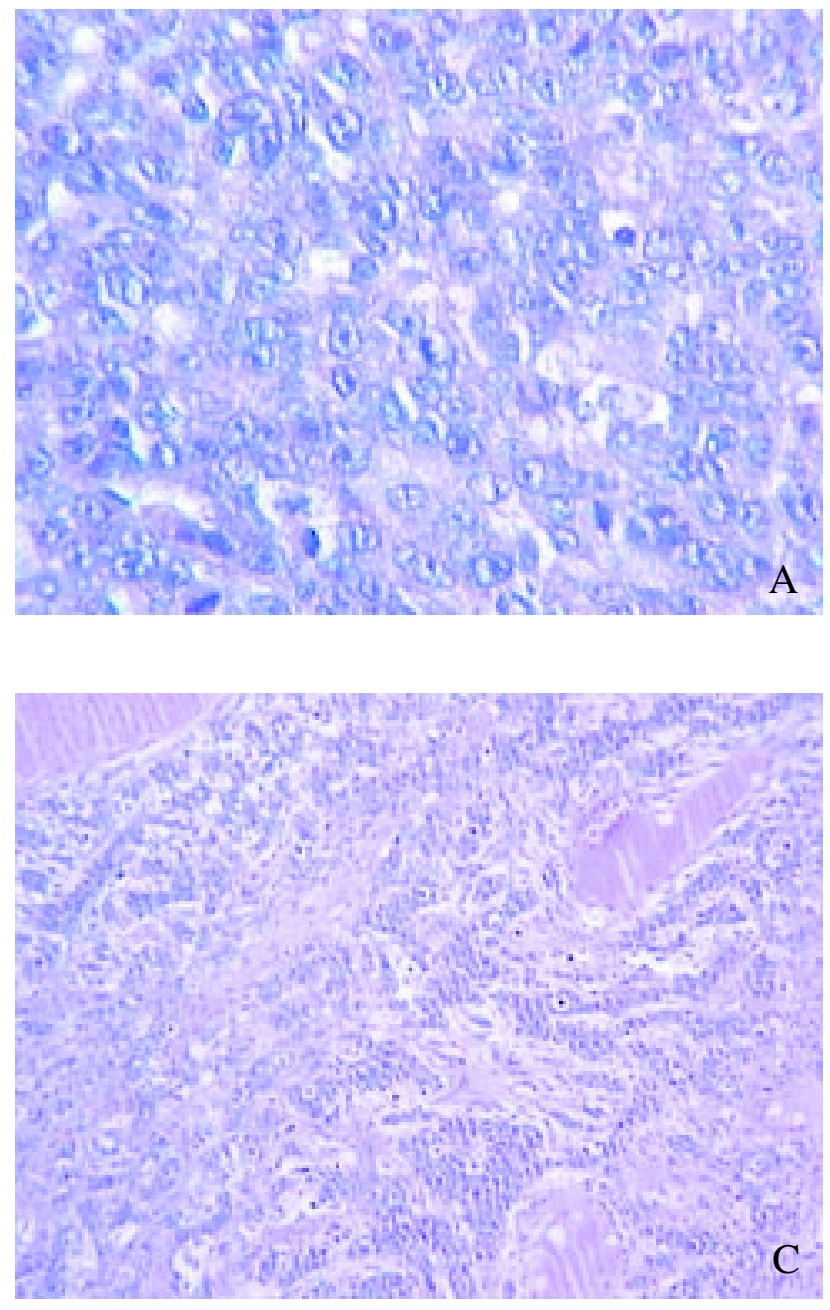

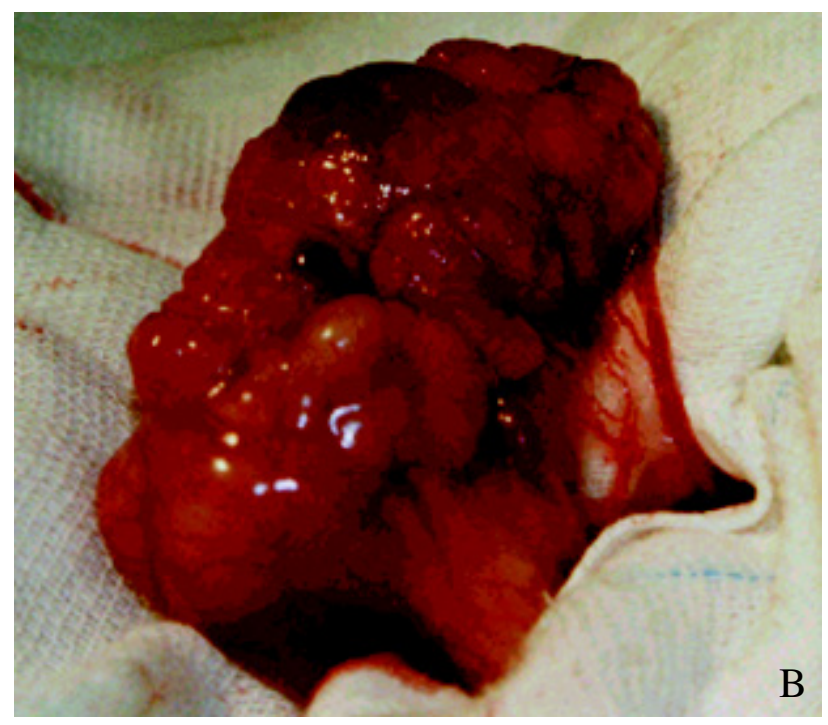

Figura 3. A - Fotomicrografia da massa mediastinal revelando timoma epitelial de células claras com epitélio primordial associado. (H\&E =100X original). (créditos Evandro de Toledo-Piza). B Laparotomia exploratória e fotomicrografia da neoplasia. Tumoração na posição anatômica do ovário direito, com superfície irregular cerebróide, de consistência sólida, apresentando formações císticas contendo líquido acastanhado. (créditos Heloisa Justen). C - Fotomicrografia de tumor da célula da granulosa, composto de células pequenas com núcleos arredondados dispostas em cordões sarcomatosos difusos sustentados por estroma fino fibrovascular. (H\&E=40X original). (créditos Evandro de Toledo-Piza). 
e parietal, estando na categoria II e $\mathrm{P}_{0}$ do estadiamento clínico [9].

Na maioria dos casos, as complicações pósoperatórias da ressecção cirúrgica do timoma são hemorragia e/ou pneumotórax [5,26]. No presente relato, apesar da decorticação junto ao parênquima pulmonar ter sido realizada apenas para biopsia incisional, esta provocou extravasamento de ar do lobo pulmonar e, subseqüente pneumotórax, sendo controlado com a permanência de um dreno intratorácico por um período de 24 horas [9]. A princípio, o planejamento do tratamento deste paciente era instituir a quimioterapia, a fim de se obter a remissão da neoplasia, para posteriormente, submete-lo à excisão cirúrgica do tumor [26]. No entanto, o acompanhamento do tratamento quimioterápico não demonstrou reações adversas e foi satisfatório como terapia única para a remissão do timoma. $\mathrm{O}$ tempo médio de sobrevida de gatos que fizeram a ressecção cirúrgica do timoma é de dezesseis meses [11]. No presente caso, o animal foi acompanhado por três anos e meio após o término da quimioterapia e não foi observada a recidiva da massa mediastinal [29], o mesmo não ocorreu com outro caso descrito pela literatura [27].

O tumor de células da granulosa tem uma notável importância clínica devido ao seu potencial em secretar grande quantidade de estrogênio, além do seu alto risco de malignidade $[10,28]$. Quando a remoção do ovário não é completa em fêmeas esterilizadas, o tecido ovariano remanescente é revascularizado e tornase funcional, podendo evoluir para processos neoplásicos, em alguns casos [5]. A exemplo deste caso, a gata era esterilizada e apresentava repetições de cios, porém não foi evidenciada a presença de metástases [1,3]. Há relato de duas cadelas esterilizadas nas quais a síndrome do ovário remanescente foi diagnosticada e, após a remoção de tecido ovariano, detectou-se a presença de tumores das células da granulosa. Nesses animais, o intervalo entre a esterilização e o aparecimento da sintomatologia da síndrome foi de seis e nove anos [25]. A ressecção cirúrgica é tratamento de escolha e oferece um bom prognóstico, salvo nos casos onde há metástase [18].

Não foi observada nenhuma correlação entre o timoma e o tumor de células da granulosa na gata. Possivelmente, estes dois tipos de neoplasias foram duas manifestações individuais [17].

No timoma classificado na categoria II tem-se como opção terapêutica à quimioterapia como tratamento único, empregando-se a ciclofosfamida, a vincristina e a prednisona. Tal tratamento minimiza os riscos do desenvolvimento de pneumotórax, bem como da excisão cirúrgica incompleta da massa tumoral.

A existência do tumor de célula da granulosa deve ser considerada no diagnóstico diferencial de distúrbios comportamentais em gata, mesmo naquelas, que foram submetidas à esterilização.

\section{NOTAS INFORMATIVAS}

${ }^{1}$ Vetaset $^{\circledR}$, Fort Dodge Saúde Animal Ltda. Rua Luis Fernando Rodrigues, 1701. CEP 13065-858 - Campinas, SP/Brasil.

${ }^{2} V_{\text {Valium }}{ }^{\circledR}$, Roche. Av. Engenheiro Billings, 1729. CEP 05321900 - Rio de Janeiro, RJ/Brasil.

${ }^{3}$ Dormonid $^{\circledR}$, Roche. Av. Engenheiro Billings, 1729. CEP 05321900 - Rio de Janeiro, RJ/Brasil.

${ }^{4}$ Temgesic $^{\circledR}$, Schering-Plough. Estrada dos Bandeirantes, 3091. CEP 22775-111 - Rio de Janeiro, RJ/Brasil.

${ }^{5}$ Thionembutal ${ }^{\circledR}$, ABBOT. Rua Michigan, 735. CEP 04566905 - São Paulo, SP/Brasil.

${ }^{6}$ Isoflurane ${ }^{\circledR}$, Cristália. Av. Rio Branco, 26. 20090-001 - Rio de Janeiro, RJ/Brasil.

${ }^{7}$ Oncovin ${ }^{\circledR}$, Eli Lilly. Av. Morumbi, 8264. CEP 04703-002 São Paulo, SP/Brasil.

${ }^{8} \mathrm{Genuxal}^{\circledR}$, Astra Médica. Rua Santo Antonio, 184. CEP 01314900. São Paulo, SP/Brasil.

${ }^{9}$ Meticorten ${ }^{\circledR}$ 20, Schering-Plough Veterinária - Rua Cancioneiro de Évora, 255. CEP 04708-010 - São Paulo, SP/Brasil.

\section{REFERÊNCIAS}

1 Aliakbrai S. \& Ivoghei B. 1979. Granulosa cell tumor in a cat. Journal of the American Veterinary Medical Association. 174: 1306-1308.

2 Arnbjerg J. 1980. Extra-ovarian granulosa cell tumor in cat. Feline Practice. 10: 26-32.

3 Baker E. 1956. Malignant granulosa cell tumor in a cat. Journal of the American Veterinary Medical Association. 1: 322-324.

4 Batata M.A., Martini N., Huvos A.G., Aguilar R.I. \& Beattie J. 1974. Thymomas: Clinicopathologic features, therapy, and prognosis. Cancer. 34: 389- 396.

5 Carpenter J.L., Andrews L.K. \& Holzworth J. 1987. Tumors and tumor- like lesions. In: Holzworth J. (Ed). Diseases of the Cat: Medicine and Surgery. Philadelphia: W.B. Saunders, pp.406-596.

6 Carpenter J.L. \& Holzworth J. 1982. Thymoma in 11 cats. Journal of the American Veterinary Medical Association. 181: 248-251. 
7 Couto C.G. \& Hammer A.S. 1994. Oncology. In: Sherding R.G. (Ed). The Cat: Diseases and Clinical Management. Philadelphia: WB Saunders, pp.755-818.

8 Day M.J. 1997. Review of thymic pathology in 30 cats and 36 dogs. Journal of Small Animal Practice. 38: $393-403$.

9 Fossum T.W. 1997. Surgery of the Lower Respiratory Sistem: Pleural Cavity and Diaphagm. In: Small Animal Surgery. St. Louis: Mosby, pp.701-704.

10 Giacóia M.R., Maiorka P.C., Oliveira C.M., Sinhorini I.L. \& Dagli M.L.Z. 1999. Granulosa cell tumor with metastasis in a tumor. Brazilian Journal of Veterinary Research and Animal Science. 36: 250-252.

11 Gores B.R., Berg J., Carpenter L. \& Aronsohn M.G. 1994. Surgical treatment of thymoma in cats: 12 cases (1987-1992). Journal of the American Veterinary Medical Association. 204: 1782- 1785.

12 Hardy W.D. 1981. Hematopoietic tumors of cats. Journal of the American Animal Hospital Association. 17: $932-933$.

13 Kennedy P.C. \& Miller R.B. 1993. The Female Genital Sistem. In: Jubb K.V.F., Kennedy P.C. \& Palmer N. (Eds). Pathology of Domestic Animals. 4th edn. California: Academic Press, pp.364-367.

14 Klein M.K. 1996. Tumor of the Female Reproductive Sistem. In: Withrow S.J. \& Macewen E.G. (Eds). Small Animal Clinical Oncology. 2nd edn. Philadelphia: W.B. Saunders, pp.349-350.

15 Mackey L. 1975. Clear-cell thymoma and thymic hiperplasia in a cat. Journal of Comparative Pathology. 85: 367-371.

16 Malik R., Gabor L., Hunt G.B., Church D.B., Barrs V.R., Churcher R., Dixon R.T., Huxley C. \& Canfield P.J. 1997. Benign cranial mediastinal lesions in three cats. Australian Veterinary Journal. 75: 183-196.

17 Moore A.S. \& Ogilvie G.K. 2001. Thymoma, mesothelioma, and histiocytosisl. In: Feline Oncology: A comprehensive guide to compassionate care. Trenton: Veterinary Learning Systems, pp.389-397.

18 Moore A.S. \& Ogilvie G.K. 2001. Tumors of the reproductive tract. In: Ogilvie G.K. \& Moore A.S. (Eds). Feline Oncology: A comprehensive guide to compassionate care. Trenton: Veterinary Learning Systems, pp.347-354.

19 Moulton J.E. 1990. Thymoma. Tumors in domestic animals. California: University of California Press. Ltd, pp.267-268.

20 Nielsen S.W. 1983. Classification of tumors in dogs and cats. Journal of the American Animal Hospital Association. 19: 13-52.

21 Norris H.J., Garner F.M. \& Taylor H.B. 1968. Pathology of feline ovarian neoplasms. Journal of Pathology. 97: 138-143.

22 Parker G.A. \& Casey H.W. 1976. Thymomas in domestic animals. Veterinary Pathology. 13: 353-364.

23 Patnaik A.K., Lieberman P.H., Erlandson R.A. \& Antonescu A. 2003. Feline cystic thymoma: a clinicopathologic, immunohistologic, and electron microscopic study of 14 cases. Journal of Feline Medicine and Surgery. 5: 27-35.

24 Scott D.W., Yager J.A. \& Johnston K.M. 1995. Exfoliative dermatitis in association with thymoma in three cats. Feline Practice. 23: 8-13.

25 Sivacolundhu R.K., O’HaraA.J. \& Read R.A. 2001. Granulosa cell tumour in two spayed bitches. Australian Veterinary Journal. 79: 173-176.

26 Souza H.J.M., Silva A.C., Cardoso Junior R.B. \& Toledo-Piza E. 1995. Linfoma Mediastinal linfocítico Bem Diferenciado em Gato. In: Anais do XVII Congresso Brasileiro de Clínicos Veterinários de Pequenos Animais (Espírito Santo, Brasil). p.118.

27 Souza V.C., Souza H.J.M., Souza E.L., Leivas R.M. \& Toledo-Piza E. 1999. Timoma linfo-epitelial em gato. Relato de caso. In: Anais do I Congresso Internacional de Medicina Felina (Rio de Janeiro, Brasil). p.19.

28 Stein B.S. 1981. Tumors of the feline genital tract. Journal of the American Animal Hospital Association. 17: $1022-1025$.

29 Willard M.D., Tvedten H., Walshaw R. \& Aronson E. 1980. Thymoma in a cat. Journal of the American Animal Hospital Association. 176: 451-453.

30 Withrow S.J. 1996. Thymoma. In: Withrow S.J. \& Mac Ewen E.G. (Eds). Small Animal Clinical Oncology. 2nd edn. Philadelphia: W.B. Saunders, pp.530-532.

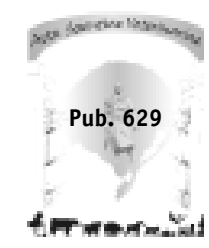

